\title{
Procurement risk management practices and supply chain performance among mobile phone service providers in Kenya
}

\author{
Emily Adhiambo Okonjo ${ }^{a}$, Peterson Obara Magutu ${ }^{\mathrm{b}}$ and Richard Bitange Nyaoga ${ }^{\mathrm{c}^{*}}$
}

${ }^{a}$ Postgraduate Student, Department of Management Science, University of Nairobi, Nairobi, Kenya

${ }^{b}$ Lecturer, School of Business, Department of Management Science, University of Nairobi, Nairobi, Kenya

${ }^{c}$ Lecturer, Department of Accounting, Finance and Management Science, Egerton University, Nakuru, Kenya

\section{H R O N I C L E}

Article history:

Received October 28, 2015

Received in revised format

November 28, 2015

Accepted December 29, 2015

Available online

December 30, 2015

Keywords:

Procurement risk management

practices

Supply chain performance

Mobile phone service providers

and Kenya

\section{A B S T R A C T}

The aim of this study was to establish the relationship between procurement risk management practices and supply chain performance among mobile phone service providers in Kenya. The study specifically set out to establish the extent to which mobile phone service providers have implemented procurement risk management practices and to determine the relationship between procurement risk management practices and supply chain performance. The study adopted a descriptive study design by collecting data from the four (4) mobile telecommunication companies in Kenya using a self-administered questionnaire. Means, standard deviation, and regression analysis were used to analyze the data collected. The study established that most of the mobile phone service providers in Kenya had implemented procurement risk management practices. It was also clear that there was a very significant relationship between procurement risk management practices and supply chain performance.

\section{Introduction}

Given today's turbulent supply markets and volatile, the pan-global business environment, corporate buyers need to make consistently superior decisions. Developing a formal and structured risk management capability for procurement is an outstanding way to do just that (Olsha, 2010). One consequence of Procurement Risk Management (PRM) is that purchase risk has emerged as a comprehensive topic in its right rather than being a facet of particular but fragmented procurement tasks. Dynamic supply chains advocate for continuously improving performance in the organization. Continuous improvement is a major challenge to many manufacturers, suppliers, and retailers who aim at achieving and sustaining competitiveness (Cai et al., 2009). It was until around three decades ago when pioneers like Wal-Mart started to view their supply chain performance not as a cost-minimizing tool but as their core competencies. Currently, many major companies like Dell, Amazon.com, UPS, 
and Zara have supply chains that play a crucial role in creating competitive advantage in the market. These companies exploit their novel supply chain designs and practices to meet and exceed their customers' needs and expectations better than their competitors and hence gain competitive advantage and higher profits (Elahi, 2010).

The mobile phone service providers in Kenya are regulated by the Communications Authority of Kenya (CA). CA is mandated to license all systems and services in the communications industry, including telecommunications, postal/courier, and broadcasting. The CA executes its mandate along with its establishing Act, The Kenya Communications Act (No. 2 of 1998) and as amended by the Kenya Communications (Amendment) Act, 2009 ("www.ca.go.ke," n.d.). It provides the framework for regulating the communications sector in Kenya ("www.ca.go.ke," n.d.). Mobile phone telephony service in Kenya started in the year 2000 when both Kencell, rebranded as Celtel in 2004 and Zain in 2008 and currently Airtel, and Safaricom were launched (www.ca.go.ke). The two companies started off with a lot of competition right from the beginning with the significant challenge of how to approach an unpredictable market with a very new service that had never been in Kenya. Safaricom's CEO chose to target the low-income earners then while Kencell's then CEO targeted the lucrative group in the market (Reuben, 2009).

According to the Communications Authority's Q 3 year 2013-2014 Quarterly sector report, there were four mobile phone service providers in Kenya as of March 2014. They are Safaricom Ltd that is $40 \%$ owned by the UK-based Vodafone, $35 \%$ by the Kenyan government, and public subscription of $25 \%$, currently dominates the market with a market share of $67.7 \%$. It is followed by Airtel which is owned by Bharti of India with a $16.5 \%$ market share. Telkom Orange, which is partly owned by France Telecom and the Kenyan government, enjoys a 7.7\% market share, and the Indian based Essar Telecom's YU enjoys $8 \%$ market share. Other players in the mobile phone service industry include the Value Added Services (VAS) companies, the businesses using commercial mobile products and, of course, the customers. Recently, CA issued Equity Bank Kenya with a mobile phone service operating license. This means that the bank can have its mobile network through which it can undertake money transfer services. The move comes as a set to step up the battle for control of Kenya's multi-millionshilling mobile money platform. Essar (YU) has however decided to exit the turbulent market with other mobile phone service providers in the country eyeing the purchase of their infrastructure. The mobile phone service industry is among the fastest growing industries in Kenya. There were 31.8 million registered mobile cell phone subscribers by the end of March 2014 with a projected growth rate of $6.8 \%$ per annum ("www.ca.go.ke," n.d.). Currently, Kenya is ranked as one among the most advanced countries in the field of mobile telecommunication industry in Africa. The cellular phone industry in Kenya has continued to transform the lives of many citizens through increased penetration of on mobile subscriptions, mobile data services on the $3 \mathrm{G}$ platform as well as mobile banking and payment (“www.ca.go.ke," n.d.).

\section{Literature Review}

A high risk-aware procurement process provides the impetus for competitive advantage, with the ability to capitalize rather than suffer from the occurrence of unexpected events (Russill, 2008). Supply chain management is one of the most strategic functions of an organization that can be capitalized on to gain a sustainable competitive advantage in the marketplace. The revolutions in technology and business practices have also brought a revolution in the world of supply chain management by organizations (Gichui, 2013).

Corporations should search for new business paradigms to gain a sustainable competitive advantage in the marketplace. There are different examples available such as Theory of Constraints (TOC), Total Quality Management (TQM), Supply chain management practices adopted by corporations for cutting costs, increasing performances, and beating the competition. Information is now a competitive 
advantage as well as a "challenge" for businesses in the marketplace (Gichui, 2013). Information has enabled firms to re-engineer activities and practices for being competitive in the market. The above revolutions have led to improvement in the performance of the supply chain. The supply chain consists of the processes that are involved in providing solutions to customer problems by firms directly or indirectly. A supply chain of an organization includes suppliers, manufacturers, and channel intermediaries like wholesalers/retailers (Awad \& Nassar, 2010).

CIPS (2012) argues that an organization that has a proper procurement risk management system can gain on strategic commercial decision-making areas such as the outsourcing of business processes and functions, which in some organizations may be taken without the involvement of procurement expertise. Such decisions always have a positive impact on the performance of an organization's supply chain although the focus was not on supply chain performance. Russill (2008) also provides a short guide to procurement risk management since, in most organizations, procurement is not treated as a strategic tool in helping organizations gain competitive advantage. He posits that most companies get pre-occupied on managing the people and assets employed in the business and on satisfying their customers failing to understand the supply chains. Procurement risk management equips the organization with the ability to capitalize, rather than suffer, from the occurrence of unexpected events.

In conclusion, by integrating Procurement Risk Management in their activities, procurement professionals and practitioners will be in a better positioned to engage with top management concerning their organizations' strategic agenda and corporate governance (Dockeary \& Lacy, 2013). While the purported goal of procurement risk management is to derive a competitive advantage, it is not clear whether the procurement risk management practices of firms are always strategically aligned with their overall competitive strategy.

\subsection{Procurement Risk Management Practices}

Procurement risk exists for an organization "when supply market behavior, and the organization's dealings with suppliers, create outcomes that harm company reputation, capability, operational integrity and financial viability"(Russill, 2008). Olsha (2010) identifies these procurement risks as; a company's dependence on a supplier, unanticipated price volatility of raw material, supplier quality problems, supply chain disruptions, unexpected price volatility through currency exchange rates, supplier bankruptcy, legal/regulatory issues and supplier dependency on a company. Procurement risk management practices are the measures taken including changes to behaviors, procedures, and controls that minimize procurement risks or reduce them to an acceptable level (Russill, 2008). The risk management framework applied to procurement involves Risk anticipation, Risk Monitoring, and Risk Mitigation.

Effective procurement risk management practice requires an understanding of the relationship between procurement and organizational objectives (Dockeary \& Lacy, 2013). Supply chain performance is the core competency tool for meeting the organizational goals (Elahi, 2010). Volatility is expected to remain high within procurement's environment shortly, and it will affect supply chain performance (Olsha, 2010). A growing number of suppliers are running into financial trouble given the declining orders, increasing raw material costs, and tightened credit markets. Thus, procurement needs to cut costs but perhaps in some companies, the greater job is identifying troubled suppliers and moving to mitigate the risk (Trkman \& McCormack, 2010).

The business environment within which the mobile sector operates has been very volatile. Political anxieties, social reforms, competition from new entrants, technological advancement, and globalization are some of the challenges that have significantly affected the growth of this sector. As such, it is very important for a company to establish a competitive advantage that is sustainable, meaning environmental changes do not easily erode it or imitated by existing and potential competitors (Kamande, 2010). 
Pochard (2003) indicated that multiple sourcing is often cited as a possible solution to protect against "disruption in supply". Regularly negotiating transactions can lead to satisfaction or dissatisfaction with the relationship on the part of the supplier and the business buyer. This power, in turn, squeezes profitability out of an industry if it is unable to recover these cost increases from its pricing. The mobile phone service industry in Kenya is evolving fast due to the rapidly changing needs of the customers in this sector (Kamande, 2010).

Christopher and Lee (2004) indicate that Managing risks in the modern environment is becoming increasingly challenging. Procurement should consider insurance as an option to leverage against uncertainties such as loss or damage to goods in transit or failure to meet liabilities of third parties. The mobile phone service providers in Kenya procure globally, high-value capital infrastructure for managing the networks through base stations.

\subsection{Supply Chain Performance}

Supply chain performance is defined as the entire chain's ability to meet end-customer needs through product availability and responsive, on-time delivery (Gunasekaran et al., 2004). Simchi-Levi (2003) defines it as the operational excellence to deliver leading customer experience. The performance of a supply chain is influenced by external factors, corporate supply chain factors, and management of extended supply chain. Organizations have moved from individual company performance to supply chain performance to (or "intending to") improving the bottom line performance of the entire chain (Gunasekaran et al., 2001).

There are various studies on supply chain performance. Authors like Spekman and Jr (1998) looked at a performance given inventory, time, order fulfillment, quality, and customer focus and customer satisfaction. Qrunfleh and Tarafdar (2013) looked into six constructs approach of supply chain practices such as a strategic supplier partnership, customer relationship, information sharing, information quality, lean internal practices, and postponement. Gunasekaran et al. (2004) indicate that there are both financial and non-financial measures looking into process and management based metrics. Shepherd and Günter (2006) categorize supply chain performance measures into supply chain processes and quantitative or qualitative measures.

Stewart (1995) indicated that Supply Chain Performance can be measured in the context of supply chain activities/processes such as plan, source, make/assemble, and delivery/customer satisfaction. Gunasekaran et al. (2004) consider these activities at various levels of management - strategic, tactical, and operational levels. Smith (2012) indicated that supply chain system responds rapidly to changes in product volume demanded by customers and to changes in product mix demanded by customers. Kingori (2013) indicates that the Supply Chain Management is highly correlated with Supply Chain practices and e-Procurement applications.

The Key performance indicators (KPIs) of a supply chain's performance has both quantitative and qualitative aspects (Dockeary \& Lacy, 2013). The achievement or non-achievement of these indicators can be directly traced to procurement practices. For example, quantitative KPIs such as cost and time can be directly related to the cost of raw materials and delivery times by suppliers. Qualitative KPIs such as the degree of satisfaction expressed by customers emanate from procurement's ability to develop the correct specifications on orders for resale. The performance of a supply chain is therefore mainly influenced by procurement practices.

Gunasekaran et al. (2004) argue that a supply chain performance measurement system that consists of a single performance measure is inadequate since it is not inclusive, ignores the interactions among important supply chain characteristics, and ignores critical aspects of organizational strategic goals. Strategic goals involve key elements that include the measurement of resources, output, and flexibility. Resources measures (cost) and output measures (generally customer responsiveness) have been widely 
used in supply chain models. Although flexibility has been limited to application to supply chains, many advantages exist to a flexible supply chain.

Gichuhi (2011) indicated that many metrics used in supply chain performance evaluation have been designed to measure operational performance, evaluate improved effectiveness, and examine the strategic alignment of the whole supply chain management. However, since many measurement systems lacked strategy alignment, a balanced approach, and systemic thinking, they had difficulty in systematically identifying the most appropriate metrics. The primary focus of this paper was qualitative and quantitative measures.

\subsection{Problem of Research}

The interest of the study has been motivated by the gap between Procurement Risk Management practices and the research in this area. Procurement Risk Management practice entails taking measures that remove procurement risks or reduce them to what is considered to be an acceptable level including changes to behaviors, procedures, and controls. However, risk management in procurement requires efforts beyond what most companies are doing - and to identify leading practices, metrics and solutions (Olsha, 2010). Contemporary business organizations are finding it essential to develop procurement risk management practices to prepare for uncertainties in the supply and demand patterns and achieve a sustainable competitive edge. However, most Procurement functions have not moved as quickly to address supply chain efficiency as some organizations have demanded (KPMG, 2011).

The mobile telecommunications' supply chains have undergone significant shifts during the past decade and are still turbulent (Agrell et al., 2004). Stiff competition has also faced the mobile phone service providers in Kenya due to globalization and advancement in technology (Gesimba, 2012). The bulk of the performance in the supply chains can be directly linked to procurement as a process. The exposures facing procurement can significantly disrupt the entire supply chain's performance through a company's drop in market share, drop in revenue, increase cost and negatively impact production distribution.

Some studies have been carried out on supply chain risk management and supply chain performance while there are no studies on procurement risk management practices and supply chain performance. Ghadge et al. (2013) indicated that the systems approach for modeling supply chain risks predicts the failure points and their overall risk impact in the supply chain network. This study has failed to indicate practices that can be carried out to mitigate these risks affecting supply chain performance hence there is a need to know if procurement risk management practices have an impact on supply chain performance.

Local studies have also been carried out on supply chain risk management and supply chain performance. Smith (2012) established that outsourcing plays a significant role in uplifting the supply chain performance of the mobile phone companies. This study was biased to outsourcing and hence addresses it as the only factor affecting supply chain performance. Elahi (2010) indicated that companies should seek risk management capabilities from a strategic point of view so as to achieve competitive advantage and overall organizational performance. These studies have failed to address procurement risk management practices that can be carried out to mitigate these risks affecting supply chain performance. Thus, there is a need to know if the mobile phone service providers in Kenya are aware of procurement risk management practices.

\subsection{Research Focus}

Several studies have been carried out by the mobile phone service providers in Kenya. Waburi (2010) indicated that the mobile phone service providers have significantly contributed to the economic growth 
of the Kenyan economy. For several years running, the sector has emerged to be the leading source of government revenue through taxation. For example, in 2007, the sector remitted KShs4.8 billion in taxes to the Exchequer, accounting for slightly higher than $10.89 \%$ of total GDP. Kamande (2010) indicated that mobile phone service providers have adopted several strategies that include cost leadership, differentiation, marketing strategies, diversification, expansion, technology strategies, customer service and corporate social responsibly that have all been successful to the companies. Gatobu (2012) indicated that Customer Relationship Management has a positive impact on sustainable competitive advantage within the mobile phone service industry in Kenya. Therefore, it is evident that the previous studies have not focused on the effect of procurement risk management practices on supply chain performance. To address this gap, this study focused on the effect of procurement risk management practices on supply chain performance of mobile phone service providers in Kenya. The study seeks to answer the following questions: What procurement risk management practices have been implemented by mobile phone service providers in Kenya? What is the relationship between procurement risk management practices and supply chain performance among mobile phone service providers in Kenya?

This study sought;

i. To determine the procurement risk management practices used by mobile phone service providers in Kenya; and

ii. To determine the relationship between procurement risk management practices and supply chain performance of mobile phone service providers in Kenya.

\subsection{Conceptual Framework}

The literature review confirms that a lot has been done on supply chain risk management and its benefits to the organization. Whereas supply chain risk management may cut across several enterprises in the entire supply chain, it may not be the case with procurement risk management practices which focuses on the organization in question and its effects filter across to the whole chain. It is, therefore, clear that there is a need to find out the effect of procurement risk management practices of an organization on its supply chain performance.

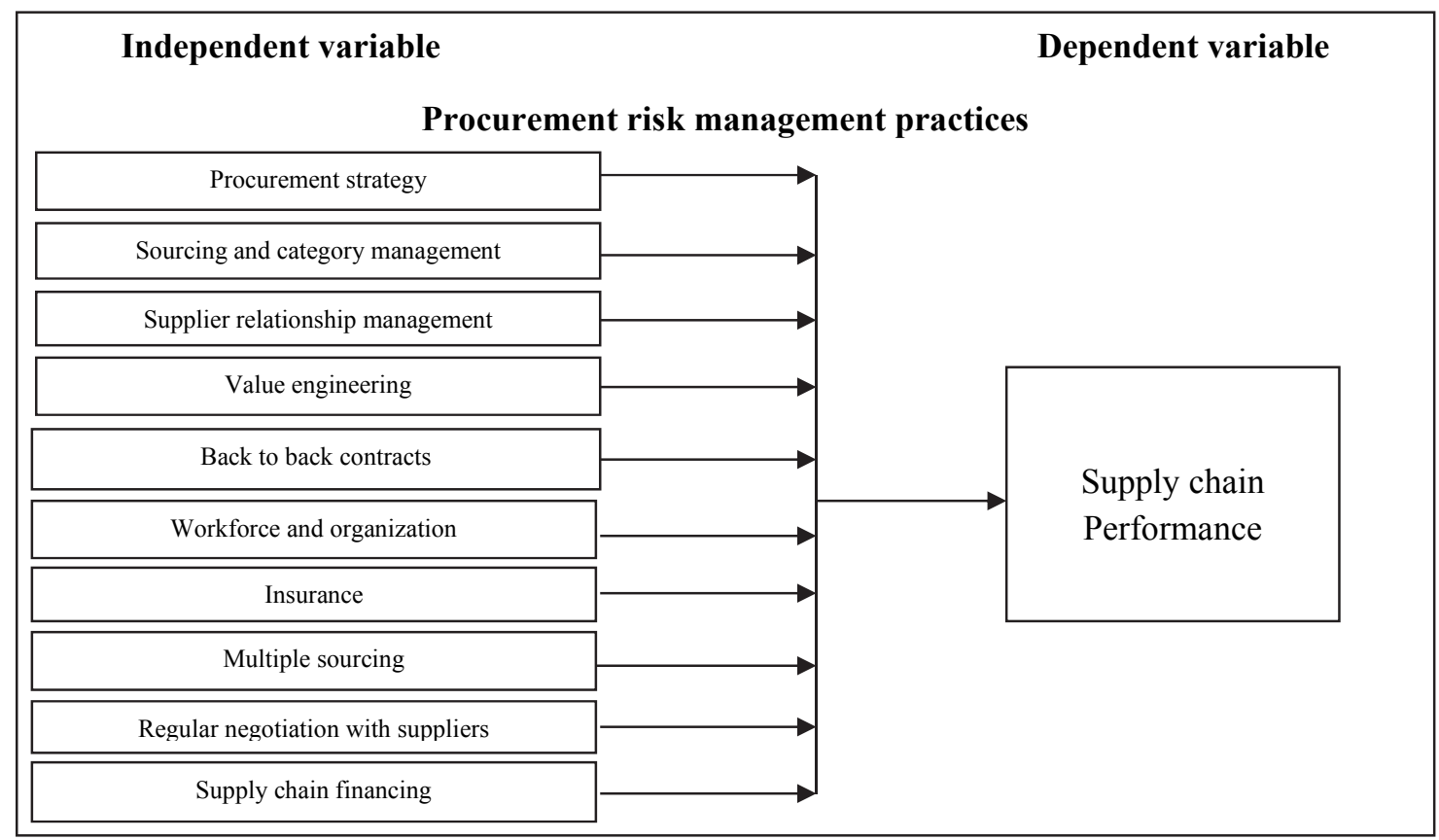

Fig. 1. Conceptual Model 
An efficient and effective supply chain will depend on the availability of a procurement strategy; sourcing and supplier relationship management; category management; workforce and organization; multiple sourcing; regular negotiation; value engineering; back to back contracts; insurance and supply chain financing.

\section{Methodology of Research}

\subsection{General Background of Research}

The research adopted a descriptive approach and a cross-sectional study. The design was considered the most appropriate since it ensured that the data obtained gave appropriate answers to the research question. A survey was used to collect information. Data was collected using a structured questionnaire and data was collected from all the four mobile phone service providers.

\subsection{Sample of Research}

The target population of the study included the four mobile phone service providers in Kenya. CA (2014) indicates that there were four licensed mobile phone service providers in Kenya as at $31^{\text {st }}$ March 2014. The four mobile phone service providers were, therefore, the target population of the study. Five respondents were picked from each of the four mobile phone service providers to participate in the study who included the Supply chain/procurement managers, the Supply Chain/Procurement officers and other members of the bureau in the same capacity such as category managers.

\subsection{Instrument and Procedures}

The researcher collected primary data from supply chain managers of all the four mobile phone service providers in Kenya and other persons within the same responsibility group. The data was obtained by use of a structured questionnaire that was self-administered. The questionnaire was in the form of Likert scale where respondents were required to indicate their views on a Likert scale of 1 to 5.

\subsection{Data Analysis}

The collected data was sorted and entered into the statistical packages for social sciences for analysis (SPSS V20). Frequencies and percentages were used to analyze demographic data. To address the first objective, descriptive statistics were used to establish the extent to which the Mobile phone service providers have adopted procurement risk management practices, i.e., using mean scores and standard deviation. The findings were presented in tables, pie charts and bar charts. To address the second objective, a multiple regression model was used in determining the relationship between procurement risk management practices and supply chain performance.

The model used is as below:

$Y=\beta_{0}+\beta_{1} x_{1}+\beta_{2} x_{2}+\beta_{3} x_{3}+\beta_{4} x_{4}+\beta_{5} x_{5}+\beta_{6} x_{6} \beta_{7} x_{7}+\beta_{8} x_{8} \beta_{9} x_{9}+\beta_{10} x_{10}+\epsilon$

where;

$\mathrm{Y}=$ Supply chain performance; $x_{1}=$ Procurement strategy practice; $x_{2}=$ Sourcing and Category Management practice; $x_{3}=$ Supplier relationship management practice; $x_{4}=$ Multiple sourcing practices; $x_{5}=$ Workforce and organization practice; $x_{6}=$ Regular negotiation with suppliers; $x_{7}=$ Risk sharing clauses; $x_{8}=$ Value engineering practice; $x_{9}=$ Insurance practice; $x_{10}=$ Supply chain financing practice; $\beta_{0}=\left(\right.$ Alpha) constant or intercept; $\beta_{1}, \beta_{2} \beta_{3}=$ Slope (Beta co-efficient) of independent variables $\left(x_{1}, x_{2}, x_{3} \ldots\right)$ and $\epsilon=$ Error term. 


\section{Results of Research}

\subsection{General Information and Profile}

The collected data was edited and cleaned for completeness in preparation for coding. Descriptive statistics were used to analyze the data. Regression analysis was used to test the relationship between the variables under study in relation to the objectives of the study. Analysis of variance (ANOVA) was used to confirm the findings of regression.

A total of 20 questionnaires were administered, and the study managed to obtain 16 completed questionnaires representing $80 \%$ response rate. The objectives of the study were: to determine the procurement risk management practices used by mobile phone service providers in Kenya and to determine the relationship between procurement risk management practices and supply chain performance of mobile phone service providers in Kenya.

The job positions held indicate that the responses were from those with hands-on experience in the company operations and were in a position to respond to the researcher's queries appropriately. In this study, Assistant Supply chain manager accounted for 35.5\% followed by Supply chain officer and Supply chain manager each at $31.2 \%$. This indicates that the researcher obtained data from reliable people by virtue of the job positions they held. The duration of service would enable the respondents to give information based on their job experience in the firm's operations. In this study, the majority $(62.5 \%)$ of the respondents had been at their respective firms for less than five years while $37.5 \%$ had been there for 5-10 years. This implies that the respondents had been working in their respective firms long enough to understand the procurement risk management practices issues sought by the study.

The researcher issued three questionnaires to three respondents in the mobile phone service providers so as to conduct a pilot study. Piloting of the research instrument was necessary to clarify the wording and grammar of the instrument so as to avoid research bias; detect ambiguous questions; to avoid misinterpretations, and to pick out in advance any problems in the methods of research. This helped to make the data used in this analysis valid.

To test the reliability of the Likert scale used in this study, a reliability analysis was done using Cronbach's Alpha as the measure. The reliability coefficient of $\alpha \geq 0.7$ was considered adequate. In this case, a reliability coefficient of 0.852 was registered indicating a high level of internal consistency for the Likert scale used. The study established that $87.5 \%$ of the respondents had been in operation for more than five years while $12.5 \%$ had less than five years of operation. This indicates that the mobile telephone service providers have been in operation long enough to understand the procurement risk issues sought by the study.

\subsection{Development of Procurement Risk Management Practices}

The respondents were asked to indicate when their firms developed their procurement risk management practices for the first times. The study established that $75 \%$ of respondents said that their firms developed their procurement risk management practices about five years ago while $25 \%$ said it was about ten years ago. This indicates that different mobile phone service providers adopted procurement risk management practices in various periods as the organizations grew.

\subsection{Implementation of Procurement Risk Management Practices}

In this section, the study sought to know the extent to which the Mobile Phone Service Providers had been practicing Procurement Risk Management Practices. The extent was measured on a Likert scale of 1-5 where: $1=$ Very Large Extent, $2=$ Large Extent, $3=$ Moderate Extent, $4=$ Small Extent and 5= 
Very Small Extent. The lower the mean, the greater the degree of the agreement and the greater the standard deviation, the higher the level of variation in the responses.

Procurement Strategy Practices: The study established that overall; Procurement Strategy Practices were used to a very large extent by the Mobile Telephone Service Providers as a way of managing procurement risk. This was evidenced by the overall mean of 1.6375. To a very large extent, the respondents agreed that effective sourcing had resulted in saving in revenue, transaction cost reduction and standardized procurement process with a mean of 1.3125. Then followed by the observation that the mobile phone services provider had a strategy that ensures procurement attracts the strongest possible field of tenders for goods and services with a mean of 1.5625. The respondents differed more on the point that the procurement plan supports delivery of the organization's vision as evidenced by the standard deviation of 0.80623 .

Sourcing Category Management Practices: The study established that there was an overall large agree from the respondents regarding Sourcing Category Management Practices. On whether the cost of buying goods and services is well managed, the respondents agreed to a very large extent as shown by the mean of 1.6875 followed by the observation that the range of products sold or purchased are broken down into discrete groups of similar related products with an average of 1.8125 indicating they agreed to a very large extent. On whether supplier evaluation, vendor portfolio analysis, supplier audits and supplier process failure mode effects and analysis are carried out regularly, the respondents agreed but only to a large extent as evidenced by the overall mean of 2.0. The latter also registered the greatest variation in the responses received as indicated by the standard deviation of 0.89443 while on whether the mobile phone service provider benefits from innovation by suppliers and has obtained increased overall value from the vendor base received the least variation in responses with a deviation of 0.77460 .

Supplier Relationship Management Practices: In regard to whether the success of mobile phone service providers can be attributed to long-term strategic partner relationships with key suppliers, the respondents agreed to a very large extent as indicated by the mean of 1.375 . On whether, the organization's desired quality of goods and services has been achieved and maintained by suppliers, the respondents also agreed to a very large extent. The least agreed on the statement was on whether the mobile phone service provider collaborates with suppliers to detect risks in the procurement process as indicated by the mean of 2.375 . Overall, the level of agreement was to a very large extent as indicated by the overall mean of 1.75 . The greatest standard deviation of 1.2042 was recorded on the statement that the mobile phone service provider collaborates with suppliers to detect risks in the procurement process indicating that it registered the greatest variation in responses as opposed to the statement that the organizations' desired quality of goods and services has been achieved and maintained by suppliers that recorded the least standard deviation of 0.51640 .

Workforce and Organization Practices: On Workforce and Organization Practices, the respondents agreed to a large extent that functions are well defined, there is clarity on who takes part in anticipation, monitoring and mitigation plans when an incident occurs and that customers are generally satisfied, and there is a reduced level of customer complaints as shown by the mean of 2.0625 for both statements. The least agreed on statements were that the organization's procurement has a certainly led procurement risk management network that coordination across regions and that the organizations' procurement risk management team handles risk management as their sole responsibility within their departments that registered a mean of 2.6875 each. Overall, the level of agreement was to a large extent as depicted by the overall mean of 2.35 . However, the responses were not necessarily clustered around the average but were dispersed as indicated by the standard deviations.

Multiple Sourcing Practice: In regard to Multiple Sourcing Practices, the statement that the mobile phone service providers can purchase identical products from different vendors received the greatest agreement with a mean of 1.5625 followed by the statement that employees and customers are generally 
satisfied with the level of service and order delivery with an average of 1.75 indicating that the level of agreement was to a very large extent. The least agreement was on the statement that there is a little dependency on suppliers that recorded a mean of 2.5625 indicating agreement to a large extent. The overall mean registered was 1.925 indicating that the overall level of agreement was to a very large extent. However, the responses were spread out as shown by the standard deviations registered.

The Practice of Regular Negotiation with Suppliers: The respondents were further prompted to indicate their level of agreement regarding various Regular Negotiation with Suppliers statements. On whether the mobile phone service providers regularly bargain with suppliers whenever there is a new order to be fulfilled, the respondents agreed to a very large extent as shown by the mean of 1.25 . On whether there exists a good relationship between the organization and its suppliers with the hope for continued future agreements, the respondents also agreed to a very large extent. However, on whether the mobile phone service provider has managed its costs and maintained profitability, the respondents only agreed to a large extent as shown by the mean of 2.0. Overall, the respondents agreed to a very large extent as indicated by the overall mean of 1.675. However, the respondents' opinions on the statements varied considerably as shown by the standard deviations recorded.

Risk Sharing Clauses (Back to Back Contracts Practice): On risk-sharing clauses, the statement that obligations of both the contractor and subcontractor are clearly spelt out in the contract was the most agreed on with a mean of 1.25 followed by the statement that both the contractor and the subcontractor bear responsibility in the event of any disruption that had a mean of 1.4375 . The statements that the mobile phone service provider interprets risk-sharing clauses in its contracts with the suppliers and that the contractor is fully protected against any risk of underperformance by the subcontractor were the least agreed on with means of 1.8125 and 2.5625 respectively. Overall, the agreement was to a very large extent as shown by the average of 1.7375 . The contractor is adequately protected against any risk of underperformance by the subcontractor was the statement that had the greatest deviation of 1.54785 while Obligations of both the contractor and subcontractor are clearly spelt out in the contract had the least.

Value Engineering Practice: To a very large extent, the respondents agreed that their organizations develop products that meet the different needs of the various customer segments with a mean of 1.6250. The organization regularly carries out a market analysis to understand the changing needs of their clients came second with a mean of 1.6875 while the statement that the changing needs of the customers are addressed during product development came third with an average of 1.75 . The overall level of agreement was to a very large extent as indicated by the overall mean of 1.7875 . The greatest disparity in responses was recorded on the statement that suppliers work closely with engineers to developing alternative bills of materials that had a standard deviation of 1.06262 while the statement that the mobile phone service provider conducts value analysis at the design engineering stage of its products registered the least with a deviation of 0.75000 .

Insurance Practice: Regarding the insurance practice, the respondents agreed to all statements to a very large extent. The statement that the mobile phone service provider has insurance arrangements with an insurance company was the most agreed on statement with a mean of 1.25 followed by the statement that insurance premiums are regularly paid with a mean of 1.3125 and then the statement that the mobile phone service provider ensures all goods in transit with an average of 1.375. This section also registered the least standard deviations with the statement that the organization engages in Just-in-time global procurement with a deviation of 0.80623 while the statement that the mobile phone service provider has insurance arrangements with an insurance company had the least deviation indicating that the responses were more clustered towards the mean.

Supply Chain Financing Practice: In regard to Supply Chain Financing Practice, the study established that on whether working capital of both the supplier and the buyer is never affected where high-cost 
capital supplies are involved, the respondents agreed to a great extent followed by the statement that loans are advances based on the creditworthiness of the mobile phone service provider and not the supplier with a mean of 2.625. On whether letters of credit are undertaken where necessary and on whether vendor financing is practiced where the suppliers have the capacity, the respondents agreed only to a moderate extent as shown by the overall mean of 3.5000 and 3.5625 respectively. High standard deviations were also recorded indicating the responses were significantly spread away from the average. Vendor financing is practiced where the suppliers have the capacity is the statement that recorded the greatest disparity while the statement that working capital of both the supplier and the buyer is never affected where high-cost capital supplies are involved had the least disparity.

\subsection{Procurement Performance}

In this section, the study sought to know how the respondents rated the procurement performance of the Mobile Phone Service Providers they worked for. Different parameters were used to measure procurement performance. The extent was measured on a Likert scale of 1-5 where: 1= Very Large Extent, 2= Large Extent, 3= Moderate Extent, 4= Small Extent and 5= Very Small Extent. The lower the mean, the greater the degree of procurement performance. Over the five-year period, full delivery on requests and proposals was the most highly rated procurement performance parameter with a mean of 1.3077 indicating it was estimated to be performing well to a very large extent. Other parameters measured to a very large extent are Accuracy of orders delivered, Order cycle time, Quality of orders, Profit maximization, Stock available, Operational efficiency, Supplier response time, Revenue maximization, Customer Satisfaction and Stock turnover. Their means are as shown in Table 1. The least rated aspect was that Employee motivation/satisfaction that recorded a mean 2.5. The standard deviations indicate that over the five-year period, the level of procurement had been fluctuating. Overall, procurement was rated to be performing well to a very large extent as indicated by the overall mean of 1.749 .

\section{Table 1}

Procurement Performance

\begin{tabular}{lll}
\hline Procurement Performance & Mean & Std. Deviation \\
\hline Full delivery on requests and proposals & 0.3077 & 0.48038 \\
Accuracy of orders delivered & 1.3846 & 0.65044 \\
Order cycle time & 1.4167 & 0.66856 \\
Quality of orders & 1.4615 & 0.66023 \\
Profit maximization & 1.5455 & 1.21356 \\
Stock available & 1.5833 & .90034 \\
Operational efficiency & 1.6154 & 1.12090 \\
Supplier response time & 1.6154 & 0.76795 \\
Revenue maximization & 1.6364 & 0.92442 \\
Customer satisfaction & 1.7692 & 0.72501 \\
Stock turnover & 1.7692 & 0.92681 \\
Time to market & 2.0833 & 0.79296 \\
Cost minimization & 2.0909 & 1.70027 \\
Market share maximization & 2.4615 & 1.56074 \\
Employee motivation/satisfaction & 2.5000 & 1.31426 \\
Overall Mean & 1.7494 & 0.9605 \\
\hline
\end{tabular}

\subsection{Relationship between Procurement Risk Management Practices and Supply Chain Performance}

The study sought to establish the relationship between procurement risk management practices and supply chain performance. Regression analysis was conducted using Statistical Package for Social Sciences. The results obtained are presented and discussed below; 
Table 2

Model Summary

\begin{tabular}{lcccc}
\hline Model & $\mathrm{R}$ & $\mathrm{R}$ Square & Adjusted R Square & Std. Error of the Estimate \\
\hline 1 & $0.826 \mathrm{a}$ & 0.683 & 0.646 & 0.94551673 \\
\hline $\begin{array}{l}\text { a. Predictors: (Constant), Procurement strategy practice, Sourcing and Category Management practice, Supplier relationship management practice, } \\
\text { Multiple sourcing practice, Workforce and organization practice, Regular negotiation with suppliers, Risk sharing clauses, Value engineering practice, } \\
\text { Insurance Practice, Supply chain financing practice. }\end{array}$
\end{tabular}

In a model summary, the " $R$ " value is used to indicate the strength and direction of the relationship between the variables. A positive or negative sign indicates the direction of the relationship. In this case the $\mathrm{R}=0.576$. This means there was an overall strong and positive relationship between the variables. The adjusted R-Square in the study was found to be 0.646 . This value indicates that the independent variables can explain $64.6 \%$ of the variance in procurement performance. It is clear that they contribute to a relatively significant extent to the level of performance that is achieved in the procurement performance of organizations. It, therefore, suffices to conclude that procurement risk management practices are relatively essential in enhancing the procurement performance of an organization given that there is an unexplained variance of $35.4 \%$.

Unstandardized Coefficients of a determination under the B column are used to substitute the unknown beta values. The beta values indicate the direction of the relationship. A positive sign indicates a positive relationship while a negative sign indicates a negative relationship. The significant values ( $p-$ value) under sig. Column indicates the statistical significance of the relationship. A p-value of less than 0.05 is recommended as it signifies a high degree of confidence. A value above 0.05 indicates that the relationship maybe as a result of coincidence.

Table 3

Regression Coefficients

\begin{tabular}{lcccccc}
\hline \multirow{2}{*}{ Model } & \multicolumn{2}{c}{ Unstandardized } & Standardized & & \\
\cline { 2 - 3 } (Constant) & $\mathrm{B}$ & Std. Error & Beta & $\mathrm{t}$ & Sig. \\
\hline Procurement strategy practice & 0.857 & 0.116 & & & 10.164 & 0.000 \\
Sourcing and Category & 0.279 & 0.152 & 0.273 & & 2.835 & 0.047 \\
Supplier relationship management practice & 0.267 & 0.151 & 0.247 & 2.049 & 0.120 \\
Multiple sourcing practices & 0.331 & 0.223 & 0.321 & & 2.250 & 0.0876 \\
Workforce and organization practice & 0.367 & 0.366 & 0.353 & & 2.756 & 0.051 \\
Regular negotiation with suppliers & 0.305 & 0.296 & 0.278 & & 3.865 & 0.001 \\
Risk sharing clauses & 0.254 & 0.546 & 0.241 & & 5.658 & 0.005 \\
Value engineering practice & 0.289 & 0.468 & 0.232 & & 3.230 & 0.032 \\
Insurance practice & 0.405 & 0.233 & 0.395 & & 2.960 & 0.042 \\
Supply chain financing practice & 0.353 & 0.203 & 0.342 & 3.112 & 0.036 \\
\hline
\end{tabular}

a. Dependent Variable: Procurement Performance

In this case, seven variables were found to be statistically significant as their p-values were less than above 0.05 . Insurance practice was found to have the greatest impact as indicated by the beta value of 0.05. All the predictor variables were found to have a positive effect on procurement performance.

Procurement Performance $=0.273$ Procurement Strategy Practice +0.164 Sourcing and Category Management Practice + 0.247 Supplier Relationship Management Practice + 0.321 Multiple Sourcing Practice +0.353 Workforce and Organization Practice +0.278 Regular Negotiation with Suppliers + 
0.241 Risk Sharing Clauses +0.232 Value Engineering Practice +0.395 Insurance Practice +0.342 Supply Chain Financing Practice

The results of the regression equation show that if all the independent variables were rated zero, Procurement Performance is predicted to be 0.857. However, all the predictors had a positive relationship with the dependent variable. Analysis of variance was also done to establish the significance of the regression model.

\section{Table 4}

Analysis of Variance

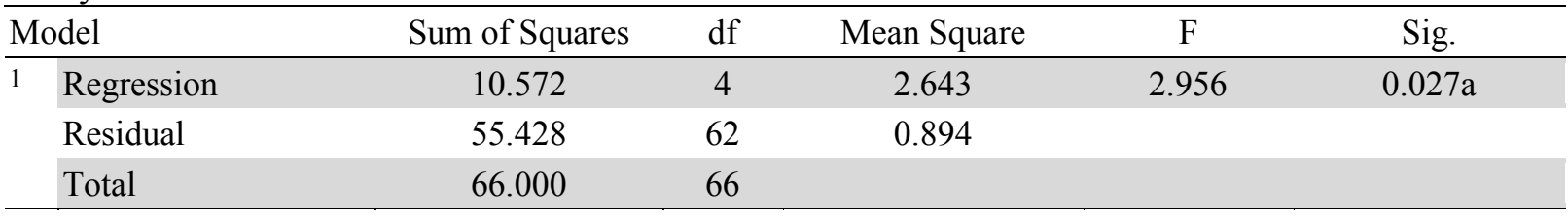

a. Predictors: (Constant), Procurement strategy practice, Sourcing and Category Management practice, Supplier relationship management practice, Multiple sourcing practice, Workforce and organization practice, Regular negotiation with suppliers, Risk sharing clauses, Value engineering practice, Insurance Practice, Supply chain financing practice. Dependent variable: Supply Chain performance

b. Dependent variable: Supply Chain performance

At $95 \%$ confidence level, a significant value (p-value) of 0.027 was registered. This shows that the regression model has a probability of less than 0.027 of giving a wrong prediction. Hence, the regression model used above is a suitable prediction model for explaining how procurement risk management practices influence supply performance.

\section{Discussion}

The research findings further indicated that there was a positive relationship $(\mathrm{R}=0.576)$ between procurement risk management practices and supply chain performance. The result of the study also showed that the value of adjusted R-squared was 0.646. This means that independent variables investigated in the study (procurement risk management practices) could account for or explain 64.6\% of the dependent variable, supply chain performance. The remaining $35.4 \%$ can be explained by other variables that are not under study. The degree of the vulnerability of a supply chain is determined to a large extent by the level of complexity of the network. In recent times, the complexity has increased many-fold due to firms' focus on their core competence and greater dependence on outsourcing. Olsha (2010) indicates that there is a need for a structured risk management capability within the procurement organization since procurement has become an important focal point for companies' risk management concerns. He identified procurement risk management practices that impact on the performance of the organization. Therefore, the study findings support the existing literature.

Findings obtained from this study have a close correlation with what has been discussed in the literature review and particularly the theoretical framework. It has been noted that the four mobile phone service providers are finding it essential to develop procurement risk management practices to enhance their supply chain performance. Today's turbulent supply markets and volatile, the pan-global business environment has forced organizations to develop strategies to attain positive Supply Chain performance. Russill, (2008) also indicated that procurement risk management should be on top of management's agenda since there is greater awareness that risks can lurk in areas where traditionally they have not been sought. The study also indicated that procurement risk management practices could account for or explain $64.6 \%$ of the dependent variable, supply chain performance. Other variables can explain the remaining $35.4 \%$.

Smith (2012) in his study established that outsourcing plays a significant role in uplifting the supply chain performance of the mobile phone companies in Kenya. Gichuhi (2011) in her study also indicated 
that business integration has assisted the commercial banks in Kenya to enhance the performance of their supply chains. Despite the challenges faced in the implementation of procurement risk management practices, the mobile phone service providers have embraced it as a strategic tool for gaining a competitive advantage, customer satisfaction and therefore profit maximization to their shareholders.

\section{Conclusions}

The first objective of the study was to determine the procurement risk management practices used by mobile phone service providers in Kenya. The study concludes that the primary procurement risk management practices used by Mobile Telephone Service Providers are: Risk sharing where obligations of both the contractor and subcontractors are clearly spelt out in the contract clauses, developing products that meet different needs of the various customer segments to avoid the risk of financial loss, having insurance arrangements with an insurance company where insurance premiums are regularly paid, insuring all goods in transit and undertaking insurance cover against unpredictable and unavoidable natural disruptions.

The second objective was to determine the relationship between procurement risk management practices and supply chain performance of mobile phone service providers in Kenya. The study concluded that there is a positive relationship between procurement risk management practices and supply chain performance. Procurement risk management explains $64.6 \%$ of the supply chain performance.

\section{Recommendations and Suggestions for Further Research}

This study recommends the following measures to ensure continued improvement in procurement performance: The managements of the mobile phone service providers should keep on doing regular risk assessments in their supply chains as a way of averting adverse effects of uncertainty. The firms can also benchmark themselves against the best players in the world as a way of improving their supply chain risk management practices. The study further recommends that all mobile phone service providers in Kenya should endeavor to understand the procurement risk management practices fully to drive them to the undisputed performance of their supply chains. The study was concerned with establishing the relationship between procurement risk management practices and supply chain performance of mobile phone service providers. Around $64.6 \%$ of the supply chain performance can be explained by procurement risk management practices. However, the remaining $35.4 \%$ can only be explained other factors, not under consideration in this study. Therefore, there is need to establish the other factors.

Further research on the same study can be done in other countries to establish whether implementing procurement risk management practices can yield the same effect on supply chain performance of mobile phone service providers.

\section{Acknowledgment}

The authors would like to thank the anonymous referees for their comments on earlier version of this paper. 


\section{References}

Agrell, P. J., Lindroth, R., \& Norrman, A. (2004). Risk, information and incentives in telecom supply chains. International Journal of Production Economics, 90(1), 1-16.

Awad, H. A. H., \& Nassar, M. O. (2010). Supply Chain Integration: Definition and Challenges. Proceedings of the International MultiConference of Engineers and Computer Scientist, I, 1 .

Cai, J., Liu, X., Xiao, Z., \& Liu, J. (2009). Improving supply chain performance management: A systematic approach to analyzing iterative KPI accomplishment. Decision Support Systems, 46, 512-521.

Christopher, M., \& Lee, H. (2004). Mitigating supply chain risk through improved confidence. International Journal of Physical Distribution \& Logistics Management, 34(5), 388396.

CIPS. (2012). Principles and Practices of Public Procurement.

Dockeary, I., \& Lacy, B. (2013). Risky Business : an Introduction to Procurement Risk Management. CIPS.

Elahi, E. (2010). How Risk Management Can Turn into Competitive Advantage How Risk Management Can Turn into Competitive Advantage. Boston.

Gatobu, A. M. (2012). The role of customer relationship management in building competitive advantage: The case of Mobile phone operators in Kenya. The university of Nairobi.

Gesimba. (2012). Challenges and Competitive Strategies adopted by Mobile phone companies in Kenya. The university of Nairobi.

Ghadge, A., Dani, S., Chester, M., \& Kalawsky, R. (2013). A systems approach for modeling supply chain risks. Supply Chain Management: An International Journal, 18(5), 523-538.

Gichui, M. W. (2013). Business integration and supply chain performance among commercial banks in Kenya. The university of Nairobi.

Gunasekaran, A., Patel, C., \& McGaughey, R. E. (2004). A framework for supply chain performance measurement. International Journal of Production Economics, 87(3), 333-347.

Gunasekaran, A., Patel, C., \& Tirtiroglu, E. (2001). Performance measures and metrics in a supply chain environment. International Journal of Operations \& Production Management, 21(1/2), 7187.

Kamande, W. W. (2010). Competitive Strategies adopted by Mobile phone companies in Kenya. The university of Nairobi.

Kingori, M. (2013). The Effect of E-Procurement on Supply Chain Management at Teachers' Service Commission. International Journal of Social Sciences and Entrepreneurship, 3(4), 17-20.

KPMG. (2011). The Power of Procurement.

Olsha, M. (2010). High performance in Procurement Risk Management(Doctoral dissertation, Massachusetts Institute of Technology).

Pochard, S. (2003). Managing risks of supply-chain disruptions: dual sourcing as a real option (Doctoral dissertation, Massachusetts Institute of Technology).

Qrunfleh, S., \& Tarafdar, M. (2013). Lean and agile supply chain strategies and supply chain responsiveness: the role of strategic supplier partnership and postponement. Supply Chain Management: An International Journal, 18(6), 571-582.

Reuben, M. (2009). Strategic Responses to Global Challenges by Commercial Banks in Kenya.

Russill, R. (2008). A Short Guide to Procurement Risk 1 Procurement and Risk - The Big Picture. Forum American Bar Association.

Shepherd, C., \& Günter, H. (2006). Measuring supply chain performance: current research and future directions. International Journal of Productivity and Performance Management, 55(3/4), 242-258.

Simchi-Levi, D., P. K., and E. S.-L. (2003). Designing and Managing the Supply Chain: Concepts, Strategies, and Case Studies. New York: McGraw-Hill.

Smith, K. S. (2012). Outsourcing and Supply Chain Performance Among Mobile Telephone Sevice Providers in Kenya. The university of Nairobi.

Spekman, R. E., \& Jr, J. W. K. (1998). An empirical investigation into supply chain management A 
perspective on partnerships. Supply Chain Management: An International Journal, 3(2), 53-67.

Stewart, G. (1995). Supply chain performance benchmarking study reveals keys to supply chain excellence. Logistics Information Management, 8(2), 38-44.

Trkman, P., \& McCormack, K. (2010). Estimating the benefits and risks of implementing Eprocurement. IEEE Transactions on Engineering Management, 57(2), 338-349.

Waburi, N. (2010). The Contribution of mobile phones to the Kenyan Economy.

www.ca.go.ke. (n.d.).

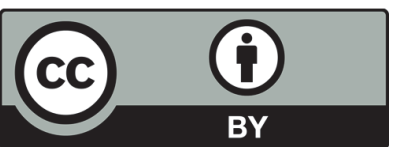

(C) 2016 by the authors; licensee Growing Science, Canada. This is an open access article distributed under the terms and conditions of the Creative Commons Attribution (CC-BY) license (http://creativecommons.org/licenses/by/4.0/). 